\title{
PERAN BRAND AWARENESS MEMEDIASI PENGARUH IKLAN TERHADAP NIAT BELI (Studi Pada Produk Pasta Gigi Merek Sensodyne di Kota Denpasar)
}

\author{
Vidya Chandra Dewi ${ }^{1}$ \\ Eka Sulistyawati $^{2}$
}

\author{
${ }^{1,2}$ Fakultas Ekonomi dan Bisnis Universitas Udayana, Bali, Indonesia \\ e-mail: vidyachandra25@gmail.com
}

\begin{abstract}
ABSTRAK
Rendahnya kesadaran masyarakat dalam mengatasi masalah gigi sensitif dengan menggunakan produk pasta gigi khusus gigi sensitif seperti merek Sensodyne membuat rendahnya niat beli terhadap produk tersebut. Niat beli pada suatu produk dapat ditingkatkan dengan memperhatikan faktor-faktor yang dapat mendorong timbulnya niat beli tersebut. Penelitian ini bertujuan dalam menjelaskan peran brand awareness memediasi pengaruh iklan terhadap niat beli. Lokasi penelitian diadakan di Kota Denpasar yang melibatkan 150 orang responden dengan metode yang digunakan yaitu purposive sampling. Metode ini dipilih karena tidak diketahui secara pasti jumlah populasinya. Pengumpulan data dilakukan melalui penyebaran kuesioner. Teknik analisis jalur dan uji sobel dipilih dalam menganalisis data. Hasil penelitian menemukan bahwa iklan berpengaruh positif dan signifikan terhadap brand awareness. Iklan berpengaruh positif dan signifikan terhadap niat beli. Brand awareness berpengaruh positif dan signifikan terhadap niat beli. Brand awareness memediasi pengaruh iklan terhadap niat beli. Pihak Sensodyne diharapkan agar mempertahankan bahkan meningkatkan kualitas iklan, sehingga dapat menimbulkan niat beli pada konsumen melalui tingkat brand awareness yang tinggi.
\end{abstract}

Kata kunci: iklan, brand awareness, niat beli

\begin{abstract}
The low public awareness in dealing with sensitive dental problems by using sensitive dentifrice-specific toothpaste products such as the Sensodyne brand makes low purchasing intentions for these products. Purchase intention on a product can be improved by taking into consideration factors that can drive the purchase intention. The purpose of this study is to explain the role of brand awareness in mediating the influence of advertising on purchase intentions. The location of the study was held in Denpasar City involving 150 respondents with the method used is purposive sampling. This method was chosen because it is not known exactly the number of population. Data collection was done through questionnaires. Path analysis technique and sobel test were selected in analyzing data. The results of the study found that advertising has a positive and significant impact on brand awareness. Advertising has a positive and significant impact on purchase intention. Brand awareness has a positive and significant impact on purchase intention. Brand awareness mediates the influence of advertising on purchase intention. Sensodyne parties are expected to maintain and even improve the quality of advertising, so it can cause purchase intention to consumers through high brand awareness level.
\end{abstract}

Keywords: advertising, brand awareness, purchase intention 


\section{PENDAHULUAN}

Pola gaya hidup manusia dalam kehidupan sehari-hari semakin bertambah luas. Aspek-aspek dalam kehidupan kini semakin berkembang, maka hal dalam kesehatan terutama gaya hidup sehat juga kian berkembang. Gaya hidup yang sehat menjadi tren tersendiri di beberapa kalangan masyarakat Indonesia, khususnya di daerah kota yang menjadi tempat tinggal bagi sebagian besar masyarakat (okezone.com). Masyarakat mulai peduli dengan isu tentang kesehatan. Perusahaan menjadi terdorong dalam menawarkan produk yang dapat menjaga kesehatan masyarakat.

Kesehatan tubuh yang dijaga oleh masyarakat salah satunya adalah kesehatan pada gigi. Hasil dari berbagai penelitian menunjukkan bahwa berbagai penyakit yang serius pada gigi disebabkan karena kurangnya memperhatikan atau menjaga kesehatan pada gigi dan mulut (cni.co.id). Masalah gigi sensitif merupakan salah satu masalah serius yang dapat terjadi pada gigi. Gigi sensitif terjadi karena gusi terbuka dan lapisan dentin di bawahnya terkena rangsangan dari luar, sehingga jika terkena panas atau dingin, maka akan terasa ngilu.

Masyarakat pada umumnya masih kurang mengetahui penyebab terjadinya gigi sensitif, sehingga sering melakukan penanganan yang kurang tepat dalam mengatasi masalah tersebut. Solusi yang dapat dilakukan untuk menangani masalah gigi sensitif, salah satunya dengan menggunakan pasta gigi khusus gigi sensitif (webkesehatan.com). Perkembangan pasta gigi kini mampu memberikan nilai tambah dan manfaat lebih bagi kebutuhan konsumen. Konsumen dapat memilih jenis pasta gigi yang sesuai dengan kebutuhannya dalam mengatasi masalah serta 
menjaga kesehatan gigi. Merek produk pasta gigi yang dihasilkan oleh beberapa produsen pasta gigi di Indonesia adalah sebagai berikut:

Tabel 1. Produsen Pasta Gigi di Indonesia

\begin{tabular}{ll}
\hline \multicolumn{1}{c}{ Merek } & \multicolumn{1}{c}{ Perusahaan } \\
\hline Pepsodent, Pepsodent Junior, Close Up & PT. Unilever Indonesia \\
Ciptadent, Zact, Systema, Kodomo & PT. Lion Wings \\
Sensodyne & PT. GlaxoSmithKline (GSK) Indonesia \\
Enzim, Enzim Kids & PT. Enzym Bioteknologi Internusa \\
Formula, ABC Dent & PT. Ultra Prima Abadi (OT Group) \\
Colgate & PT. Colgate-Palmolive Indonesia \\
Antiplaque & PT. Triple Ace Corporation \\
\hline
\end{tabular}

Sumber: Hasil Observasi pada Saluran Distribusi, 2017

Tabel 1 memperlihatkan PT. GlaxoSmithKline (GSK) Indonesia adalah perusahaan yang memproduksi produk pasta gigi merek Sensodyne. Pasta gigi merek Sensodyne ditujukan bagi orang-orang yang memiliki masalah gigi sensitif. Mengusung tagline "Enjoy Tanpa Ngilu”, Sensodyne membantu meredakan rasa sakit akibat gigi sensitif serta tahan lama dalam melindungi gigi dari sensitifitas. Data yang dilaporkan oleh Nielsen Retail Index pada perhitugan dan klaim PT. GlaxoSmithKline Indonesia berdasarkan kategori pasta gigi untuk varian gigi sensitif selama periode 2016 di pasar perkotaan Indonesia, Sensodyne merupakan pasta gigi sensitif dengan penjualan nomor satu di Indonesia (sensodyne.com). Konsumen berarti lebih memilih pasta gigi khusus gigi sensitif merek Sensodyne yang diproduksi oleh PT. GlaxoSmithKline Indonesia dalam mengatasi masalah gigi sensitif, dibandingkan dengan merek pasta gigi khusus gigi sensitif lainnya.

Produk yang diproduksi oleh perusahaan akan dipasarkan melalui iklan dengan tujuan untuk memperkenalkan dan menawarkan keunggulan produk pada konsumen. Iklan merupakan salah satu media promosi yang dapat digunakan sebagai alat untuk pengantar pesan yang bertujuan untuk membentuk dan merubah 
perilaku konsumen (Gunawan dan Dharmayanti, 2014). Konsumen menjadi peduli dan perhatian pada iklan yang memberikan informasi mengenai suatu produk yang bermanfaat bagi mereka, sehingga dapat menimbulkan niat beli pada konsumen.

Perhatian serta daya ingat dapat meningkat ketika konsumen menerima informasi dalam iklan. Perusahaan perlu melakukan pendekatan kepada konsumen dalam upaya membentuk kesadaran merek (brand awareness) di benak konsumen, agar mudah mengenali merek suatu produk diantara merek lainnya. Konsumen cenderung membeli merek suatu produk yang sudah dikenal maupun yang mudah diingat dari pada produk yang masih asing bagi mereka, karena lebih terjamin dan terhindar dari resiko yang dapat merugikan serta membuat konsumen merasa lebih aman. Produk yang mudah diingat dan penggunaan simbol pada merek mampu menciptakan brand awareness (Tandjung, 2004:57).

Brand awareness yang tinggi pada suatu produk dapat menjadi pilihan awal saat konsumen memiliki niat beli terhadap produk tersebut. Konsumen pada umumnya akan mengumpulkan informasi terlebih dahulu sebelum melakukan pembelian terhadap suatu produk. Kumpulan informasi tersebut digunakan sebagai dasar penilaian dan evaluasi oleh konsumen dalam membuat keputusan untuk membeli, setelah mempertimbangkan dan membandingkan suatu produk. Informasi tentang suatu produk yang diberikan produsen akan menimbulkan keinginan konsumen untuk membeli suatu produk dengan merek tertentu (Dewa, 2015).

PT. GlaxoSmithKline Indonesia melakukan periklanan dengan menayangkan testimoni dan sosok profesional dalam bidang kesehatan gigi untuk menimbulkan niat beli pada produk pasta gigi merek Sensodyne bagi penderita gigi sensitif. 
Vidya Chandra Dewi, Peran Brand Awareness Memediasi...

Masyarakat sebagian besar tidak mengetahui bahwa mereka memiliki masalah dengan gigi sensitif, bahkan ada pula masyarakat yang tidak peduli bagaimana memecahkan masalah gigi sensitif tersebut (klikdokter.com). PT. GlaxoSmithKline Indonesia merespon kebutuhan masyarakat akan masalah gigi sensitif dengan menawarkan produk pasta gigi khusus gigi sensitif merek Sensodyne, namun kesadaran masyarakat akan penggunaan produk pasta gigi dalam mengatasi masalah gigi sensitif masih rendah yang menyebabkan kurangnya niat beli terhadap produk pasta gigi khusus gigi sensitif tersebut.

Hasil survey awal yang telah dilakukan peneliti terhadap 20 responden di Kota Denpasar menunjukkan bahwa masyarakat masih ragu dan tidak tertarik pada tayangan iklan produk pasta gigi merek Sensodyne, sehingga menyebabkan rendahnya kesadaran dan niat beli terhadap produk tersebut. Penelitian mengenai peran brand awareness memediasi pengaruh iklan terhadap niat beli pada produk pasta gigi merek Sensodyne menjadi ketertarikan peneliti untuk melakukan penelitian lebih lanjut, karena melihat sebuah fenomena bahwa kesadaran masyarakat masih rendah dalam menangani masalah gigi sensitif dengan menggunakan produk pasta gigi khusus gigi sensitif seperti Sensodyne.

Penelitian yang diteliti oleh Ering dan Pandowo (2015) menyatakan iklan memiliki pengaruh negatif dan tidak signifikan terhadap niat beli pada konsumen. Survey awal yang telah dilakukan dan berdasarkan kajian empiris dengan temuan yang tidak signifikan hubungan antara variabel yang diteliti, perlu dilakukan penelitian lebih lanjut di Kota Denpasar. Diharapkan penelitian ini dapat 
memberikan jawaban atas semua hipotesis yang dibuat oleh peneliti, agar dapat berguna bagi pihak-pihak yang membutuhkan.

Latar belakang yang telah dijabarkan, maka adapun pokok permasalahan pada penelitian ini yaitu: 1) bagaimana pengaruh iklan terhadap brand awareness pada produk pasta gigi merek Sensodyne di Kota Denpasar?; 2) bagaimana pengaruh iklan terhadap niat beli pada produk pasta gigi merek Sensodyne di Kota Denpasar?; 3) bagaimana pengaruh brand awareness terhadap niat beli pada produk pasta gigi merek Sensodyne di Kota Denpasar?; 4) bagaimana peran brand awareness memediasi pengaruh iklan terhadap niat beli pada produk pasta gigi merek Sensodyne di Kota Denpasar?

Pokok permasalahan yang telah diuraikan tersebut, maka adapun tujuan pada penelitian ini yaitu: 1) menjelaskan pengaruh iklan terhadap brand awareness pada produk pasta gigi Sensodyne di Kota Denpasar; 2) menjelaskan pengaruh iklan terhadap niat beli pada produk pasta gigi merek Sensodyne di Kota Denpasar; 3) menjelaskan pengaruh brand awareness terhadap niat beli pada produk pasta gigi merek Sensodyne di Kota Denpasar; 4) menjelaskan peran brand awareness memediasi pengaruh iklan terhadap niat beli pada produk pasta gigi merek Sensodyne di Kota Denpasar.

Penelitian ini memberikan manfaat teoritis dengan harapan hasil penelitian mampu memberikan kontribusi empiris terkait hubungan antara variabel iklan, brand awareness, dan niat beli dalam pengembangan ilmu pemasaran di Indonesia. Penelitian ini juga memberikan manfaat praktis dengan harapan hasil penelitian 
Vidya Chandra Dewi, Peran Brand Awareness Memediasi...

mampu menjadi pedoman bagi produsen dalam meningkatkan niat beli dan brand awareness melalui program iklan sebagai strategi promosi.

Iklan adalah segala bentuk penyajian dan promosi ide, barang atau jasa secara nonpersonal oleh suatu sponsor tertentu yang memerlukan pembayaran (Kotler dan Amstrong, 2012:454). Iklan mampu memotivasi emosional konsumen agar membeli sebuah produk tertentu (Priya et al., 2010). Perusahaan pada masa sekarang ini berusaha melakukan iklan sebaik mungkin agar dapat menyebarkan informasi mengenai produk dan jasa yang mereka tawarkan (Vejačka, 2012).

Brand awareness merupakan persoalan apakah nama merek tertentu muncul dalam ingatan ketika konsumen berpikir mengenai suatu kelompok produk tertentu dan terdapat kemudahan saat nama tersebut dimunculkan (Shimp, 2014:39). Menurut Jalilvand et al. (2011), brand awarenesss tertuju pada kuatnya kehadiran merek di pikiran konsumen. Brand awareness mempunyai pengaruh besar dalam pemilihan dan dapat menjadi pertimbangan sebelum memilih suatu produk (Hoyer dan Brown, 1990).

Niat beli adalah kegiatan atau perilaku seseorang yang timbul melalui responnya sehingga menunjukkan keinginan pelanggan untuk melakukan pembelian pada sebuah objek (Kotler, 2005:15). Niat beli sebagai suatu keinginan untuk dapat memiliki suatu produk apabila niat tersebut didorong oleh pengaruh akan mutu dan kualitas dari suatu produk dan adanya informasi yang mendukung keberadaan produk tersebut (Barr, 2007).

Penelitian yang dilakukan oleh Odunlami dan Akinruwa (2014) menunjukkan bahwa salah satu promosi penjualan yaitu iklan, berpengaruh positif dan signifikan 
terhadap kesadaran suatu produk. Penelitian dari Sawant (2012) juga menemukan hasil yang menyatakan bahwa iklan dapat memberikan pengaruh positif signifikan dengan brand awareness. Azaria dkk. (2014), Eriko dkk. (2012), Sugiardi dan Harti (2017) mempertegas hasil penelitian tersebut bahwa iklan memiliki pengaruh positif dan signifikan terhadap brand awareness. Hasil empiris berdasarkan penelitian sebelumnya yang telah diuraikan, maka dapat diajukan hipotesis yaitu:

$\mathrm{H}_{1}$ : Iklan berpengaruh positif dan signifikan terhadap brand awareness

Gunawan dan Dharmayanti (2014) melakukan penelitian dengan hasil variabel iklan memiliki pengaruh positif dan signifikan terhadap niat beli. Penelitian dengan hasil serupa ditemukan oleh Huang dan Dang (2014), dimana iklan memiliki pengaruh positif dan signifikan terhadap niat beli. Begitu pula penelitian dari Sularso dan Erviana (2012), Rina (2014), Hemamalini dan Kurup (2014) bahwa hasil penelitian tersebut menunjukkan iklan berpengaruh positif dan signifikan terhadap niat beli. Hasil empiris berdasarkan penelitian sebelumnya yang telah diuraikan, maka dapat diajukan hipotesis yaitu:

$\mathrm{H}_{2}$ : Iklan berpengaruh positif dan signifikan terhadap niat beli

Penelitian oleh Malik et al. (2013) menyatakan brand awareness mempunyai hubungan positif yang kuat dengan niat beli. Hal yang serupa juga diteliti oleh Roozy et al. (2014), dimana hasil penelitian yang didapat adalah brand awareness berpengaruh positif signifikan dengan niat beli konsumen. Kristanto dan Brahmana (2016), Andriyanto dan Haryanto (2010), Chi et al. (2009) juga mendapatkan hasil penelitian yang menyatakan bahwa brand awareness berpengaruh positif dan 
Vidya Chandra Dewi, Peran Brand Awareness Memediasi...

signifikan terhadap niat beli suatu produk. Hasil empiris berdasarkan penelitian sebelumnya yang telah diuraikan, maka dapat diajukan hipotesis yaitu:

$\mathrm{H}_{3}$ : Brand Awareness berpengaruh positif dan signifikan terhadap niat beli

Penelitian oleh Ering dan Pandowo (2015) menyatakan iklan berpengaruh negatif dan tidak signifikan terhadap niat beli pada konsumen. Penelitian Prabawa dkk. (2017) melibatkan variabel iklan, brand awareness, dan niat beli, yang menunjukkan bahwa brand awareness secara signifikan mampu memediasi hubungan antara iklan dengan niat beli. Hasil penelitian tersebut mengindikasikan bahwa secara keseluruhan, iklan yang disertai oleh brand awareness akan mempengaruhi dan menentukan niat beli konsumen. Penelitian serupa yang diteliti oleh Yudhiartika dan Haryanto (2012), Susilo dan Semuel (2015), secara tidak langsung menjelaskan bahwa brand awareness mampu memediasi hubungan iklan dengan niat beli secara positif dan signifikan. Hasil empiris berdasarkan penelitian sebelumnya yang telah diuraikan, maka dapat diajukan hipotesis yaitu:

$\mathrm{H}_{4}$ : Brand Awareness memediasi pengaruh iklan terhadap niat beli

Landasan teori dan hasil empiris berdasarkan penelitian terdahulu telah dijabarkan, maka dapat disusun model kerangka konseptual penelitian, sebagai berikut:

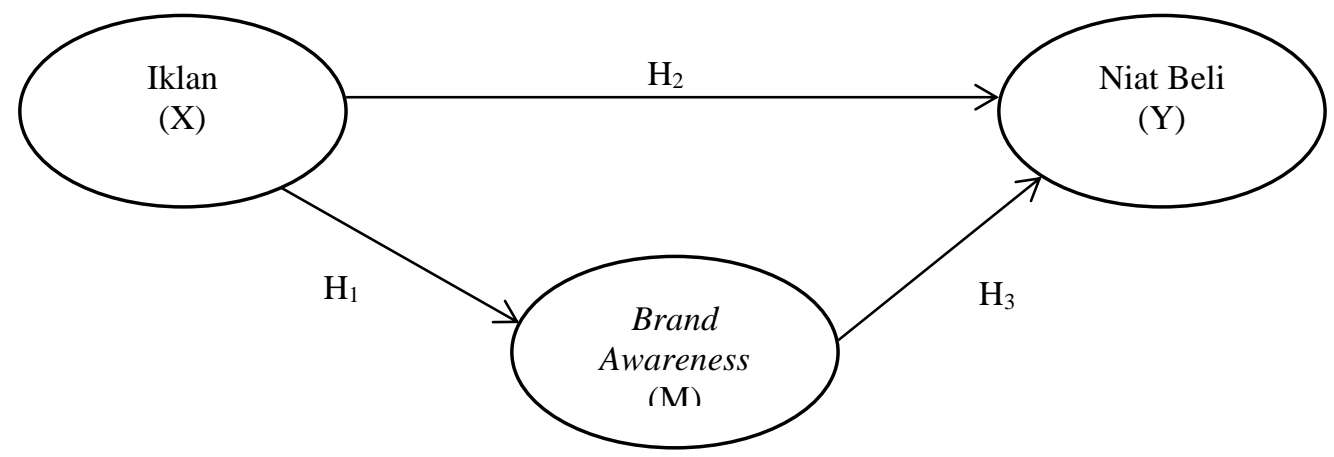

Gambar 1. Kerangka Konseptual Penelitian

Sumber: Pengembangan Penelitian Sebelumnya 


\section{METODE PENELITIAN}

Penelitian berlokasi di Kota Denpasar yang merupakan ibukota dari Provinsi Bali, dimana masyarakatnya tidak hanya berasal dari Kota Denpasar saja namun juga berasal dari berbagai daerah lain yang ada di Provinsi Bali. Jenis data dalam penelitian ini terdiri dari data kualitatif yang berupa jenis kelamin dan pekerjaan responden, serta data kuantitatif yang berupa jawaban responden terhadap pernyataan yang meliputi iklan, brand awareness, dan niat beli. Sumber data dalam penelitian ini terdiri dari sumber primer yang berupa tanggapan responden dari hasil wawancara dan jawaban kuesioner terkait variabel iklan, brand awareness, dan niat beli, serta sumber sekunder yang berupa studi empiris pada penelitian sebelumnya, berita dan data yang dikutip dari media online terkait dengan variabel yang diteliti. Variabel penelitian yang digunakan adalah variabel eksogen yaitu iklan (X), variabel mediasi yaitu brand awareness $(\mathrm{M})$, dan variabel endogen yaitu niat beli (Y).

Populasi pada penelitian ini adalah seluruh masyarakat Kota Denpasar yang belum pernah membeli produk pasta gigi merek Sensodyne. Metode purposive sampling dipilih dalam menentukan sampel dengan kriteria sampel yaitu responden yang berpendidikan minimal SMA/SMK, berdomisili di Kota Denpasar, pernah melihat atau mengetahui iklan produk pasta gigi merek Sensodyne, dan belum pernah membeli produk pasta gigi merek Sensodyne. Ukuran sampel ditentukan dengan menggunakan analisis multivariate. Jumlah anggota pada sampel minimal 10 kali dari jumlah variabel apabila menggunakan analisis multivariate (Sugiyono, 
Vidya Chandra Dewi, Peran Brand Awareness Memediasi...

2014:130). Jumlah indikator yang digunakan adalah 15 indikator, sehingga 15 indikator $\times 10=150$ orang responden.

Tabel 2. Indikator Penelitian

\begin{tabular}{|c|c|c|}
\hline Variabel & Indikator & Sumber \\
\hline $\begin{array}{c}\text { Iklan } \\
(\mathrm{X})\end{array}$ & $\begin{array}{l}\mathrm{X}_{1} \text { Mengandung daya tarik } \\
\mathrm{X}_{2} \text { Menunjukkan manfaat } \\
\mathrm{X}_{3} \text { Mengandung perhatian } \\
\mathrm{X}_{4} \text { Memunculkan keinginan untuk mencoba atau } \\
\quad \text { memiliki } \\
\mathrm{X}_{5} \text { Mengarah tindakan untuk membeli }\end{array}$ & $\begin{array}{l}\text { Djatnika (2007), } \\
\text { Wijaya (2011), dan } \\
\text { Bendixen (1993) }\end{array}$ \\
\hline $\begin{array}{c}\text { Brand } \\
\text { Awareness } \\
\text { (M) }\end{array}$ & $\begin{array}{l}\mathrm{M}_{1} \text { Pengetahuan konsumen akan kehadiran } \\
\quad \text { merek } \\
\mathrm{M}_{2} \text { Mengenal merek } \\
\mathrm{M}_{3} \text { Daya ingat konsumen akan merek } \\
\mathrm{M}_{4} \text { Mengingat ciri khas merek } \\
\mathrm{M}_{5} \text { Pilihan utama akan merek }\end{array}$ & $\begin{array}{l}\text { Humdiana (2005), } \\
\text { Liwe (2013), Yoo et } \\
\text { al. (2000), dan } \\
\text { Rangkuti (2002) }\end{array}$ \\
\hline $\begin{array}{l}\text { Niat Beli } \\
\text { (Y) }\end{array}$ & $\begin{array}{l}\mathrm{Y}_{1} \text { Ketertarikan mencari informasi lebih tentang } \\
\text { produk } \\
\mathrm{Y}_{2} \text { Mempertimbangan untuk membeli } \\
\mathrm{Y}_{3} \text { Keinginan untuk mengetahui produk } \\
\mathrm{Y}_{4} \text { Ketertarikan untuk mencoba produk } \\
\mathrm{Y}_{5} \text { Keinginan untuk memiliki produk }\end{array}$ & $\begin{array}{ll}\text { Schiffman } & \text { dan } \\
\text { Kanuk }(2004) & \end{array}$ \\
\hline
\end{tabular}

Data dikumpulkam melalui penyebaran instrumen penelitian yang menggunakan kuesioner dan akan diukur dengan 1 sampai 5 Skala Likert. Pengujian instrumen dengan menggunakan uji validitas, uji reliabilitas, dan analisis faktor konfirmatori. Teknik analisis data dengan menggunakan analisis jalur dan uji sobel.

\section{HASIL DAN PEMBAHASAN}

Uji validitas dilakukan untuk memeriksa apakah pengukuran indikator penelitian sudah tepat di dalam instrumen penelitian yang berupa kuesioner. Hasil uji validitas ditunjukkan pada Tabel 3 berikut ini.

Hasil uji validitas pada Tabel 3 memperlihatkan bahwa nilai koefisien korelasi lebih besar dari 0,3 pada masing-masing indikator tiap variabel. Korelasi tiap 
indikator dalam penelitian ini adalah valid yang artinya antara data yang diteliti dengan data yang sesungguhnya sudah tepat digunakan dalam penelitian.

Tabel 3. Hasil Uji Validitas

\begin{tabular}{cccc}
\hline Variabel & Indikator & $\begin{array}{c}\text { Koefisien } \\
\text { Korelasi }\end{array}$ & Keterangan \\
\hline Iklan & $\mathrm{X}_{1}$ & 0,956 & Valid \\
& $\mathrm{X}_{2}$ & 0,931 & Valid \\
& $\mathrm{X}_{3}$ & 0,873 & Valid \\
& $\mathrm{X}_{4}$ & 0,956 & Valid \\
& $\mathrm{X}_{5}$ & 0,928 & Valid \\
\hline Brand & $\mathrm{M}_{1}$ & 0,934 & Valid \\
& $\mathrm{M}_{2}$ & 0,943 & Valid \\
& $\mathrm{M}_{3}$ & 0,942 & Valid \\
& $\mathrm{M}_{4}$ & 0,906 & Valid \\
& $\mathrm{M}_{5}$ & 0,923 & Valid \\
\hline Niat Beli & $\mathrm{Y}_{1}$ & 0,896 & Valid \\
& $\mathrm{Y}_{2}$ & 0,901 & Valid \\
& $\mathrm{Y}_{3}$ & 0,945 & Valid \\
& $\mathrm{Y}_{4}$ & 0,945 & Valid \\
& $\mathrm{Y}_{5}$ & 0,945 & Valid \\
\hline
\end{tabular}

Sumber: Data Primer Diolah, 2017

Uji reliabilitas dilakukan untuk mengetahui adanya konsistensi alat ukur dalam penggunaannya. Hasil uji reliabilitas ditunjukkan pada Tabel 4 berikut ini.

Tabel 4. Hasil Uji Reliabilitas

\begin{tabular}{lcc}
\hline \multicolumn{1}{c}{ Variabel } & Cronbach's Alpha & Keterangan \\
\hline Iklan & 0,960 & Reliabel \\
Brand Awareness & 0,959 & Reliabel \\
Niat Beli & 0,957 & Reliabel \\
\hline
\end{tabular}

Sumber: Data Primer Diolah, 2017

Hasil uji reliabilitas pada Tabel 4 memperlihatkan bahwa nilai cronbach's alpha lebih besar dari 0,6 pada masing-masing variabel. Keseluruhan indikator variabel dalam penelitian ini adalah reliabel yang artinya telah memenuhi syarat konsistensi maupun keandalan data, sehingga dapat digunakan sebagai instrumen penelitian. 
Vidya Chandra Dewi, Peran Brand Awareness Memediasi...

Menguji kaiser mayer olkin (KMO), maka nilai yang diperoleh harus di atas 0,5 , nilai chi square yang didapat harus besar, dan tingkat signifikansi di bawah 0,05, untuk menguji apakah variabel dalam penelitian ini saling berpengaruh. Hasil uji KMO, chi square, dan significance probability ditunjukkan pada Tabel 5 berikut.

Tabel 5. Hasil Uji Kaiser Mayer Olkin (KMO) dan Bartlett's Test

\begin{tabular}{lccc}
\hline \multicolumn{1}{c}{ Variabel } & $\begin{array}{c}\text { Kaiser Mayer } \\
\text { Olkin }\end{array}$ & $\begin{array}{c}\mathbf{X}^{\mathbf{2}} \\
\text { Chi Square }\end{array}$ & $\begin{array}{c}\text { Significance } \\
\text { Probability }\end{array}$ \\
\hline Iklan & 0,903 & 649,109 & 0,000 \\
Brand Awareness & 0,884 & 597,021 & 0,000 \\
Niat Beli & 0,859 & 726,771 & 0,000 \\
\hline
\end{tabular}

Sumber: Data Primer Diolah, 2017

Tabel 5 menunjukkan bahwa tiap variabel memiliki nilai KMO di atas 0,5. Nilai $\mathrm{X}^{2}$ pada variabel iklan sebesar 649,109, variabel brand awareness sebesar 597,021, dan variabel niat beli sebesar 726,771 dengan masing-masing tingkat signifikansi 0,000, yang mengindikasikan bahwa tiap variabel dapat dinyatakan layak sebagai sebuah variabel di dalam penelitian.

Menguji measures of sampling adequacy (MSA), maka nilai yang diperoleh harus minimal 0,5, jika nilai MSA $\leq 0,5$ maka variabel dengan nilai terkecil tidak akan digunakan dalam penelitian. Hasil uji MSA secara rinci ditunjukkan pada Tabel 6 berikut.

Tabel 6. Hasil Uji Measures of Sampling Adequacy (MSA)

\begin{tabular}{cccccc}
\hline Iklan & MSA & $\begin{array}{c}\text { Brand } \\
\text { Awareness }\end{array}$ & MSA & Niat Beli & MSA \\
\hline $\mathrm{X}_{1}$ & 0,935 & $\mathrm{M}_{1}$ & 0,875 & $\mathrm{Y}_{1}$ & 0,892 \\
$\mathrm{X}_{2}$ & 0,931 & $\mathrm{M}_{2}$ & 0,906 & $\mathrm{Y}_{2}$ & 0,912 \\
$\mathrm{X}_{3}$ & 0,914 & $\mathrm{M}_{3}$ & 0,877 & $\mathrm{Y}_{3}$ & 0,898 \\
$\mathrm{X}_{4}$ & 0,884 & $\mathrm{M}_{4}$ & 0,870 & $\mathrm{Y}_{4}$ & 0,811 \\
$\mathrm{X}_{5}$ & 0,865 & $\mathrm{M}_{5}$ & 0,898 & $\mathrm{Y}_{5}$ & 0,804 \\
\hline Sumber: Data Primer Diolah, 2017 & & &
\end{tabular}


Tabel 6 menunjukkan bahwa masing-masing indikator pada tiap variabel memiliki nilai koefisien MSA lebih besar dari 0,5. Hasil tersebut mengindikasikan bahwa variabel yang digunakan dalam penelitian ini dapat dianalisis lebih lanjut.

Menguji principal component analysis (PCA), maka nilai yang diperoleh harus minimal 0,5 , jika nilai $\mathrm{PCA} \leq 0,5$ maka indikator yang diteliti dalam penelitian tidak dapat membentuk kombinasi linier. Hasil uji PCA secara rinci ditunjukkan pada Tabel 7 berikut.

Tabel 7. Hasil Uji Principal Component Analysis (PCA)

\begin{tabular}{cccccc}
\hline Iklan & PCA & $\begin{array}{c}\text { Brand } \\
\text { Awareness }\end{array}$ & PCA & Niat Beli & PCA \\
\hline $\mathrm{X}_{1}$ & 0,757 & $\mathrm{M}_{1}$ & 0,802 & $\mathrm{Y}_{1}$ & 0,804 \\
$\mathrm{X}_{2}$ & 0,759 & $\mathrm{M}_{2}$ & 0,742 & $\mathrm{Y}_{2}$ & 0,786 \\
$\mathrm{X}_{3}$ & 0,822 & $\mathrm{M}_{3}$ & 0,832 & $\mathrm{Y}_{3}$ & 0,796 \\
$\mathrm{X}_{4}$ & 0,829 & $\mathrm{M}_{4}$ & 0,815 & $\mathrm{Y}_{4}$ & 0,860 \\
$\mathrm{X}_{5}$ & 0,863 & $\mathrm{M}_{5}$ & 0,738 & $\mathrm{Y}_{5}$ & 0,849 \\
\hline \multicolumn{5}{l}{ Sumber: Data Primer Diolah, 2017}
\end{tabular}

Tabel 7 menunjukkan bahwa masing-masing indikator pada tiap variabel memiliki nilai koefisien PCA lebih besar dari 0,5. Hasil tersebut mengindikasikan bahwa indikator pada variabel yang diteliti dalam penelitian ini dikatakan dapat membentuk kombinasi linier.

Menguji total variance explained, maka nilai yang diperoleh harus minimal 0,6 , jika nilai total variance explained $\geq 0,6$ maka dapat digunakan untuk menentukan berapakah faktor yang mungkin dapat dibentuk. Hasil uji total variance explained secara rinci ditunjukkan pada Tabel 8 berikut.

Tabel 8. Hasil Uji Total Variance Explained

\begin{tabular}{lc}
\hline \multicolumn{1}{c}{ Faktor } & Total Variance Explained \\
\hline Iklan & 80,591 \\
Brand Awareness & 78,560 \\
Niat Beli & 81,892 \\
\hline Sumber: Data Primer Diolah, 2017
\end{tabular}


Tabel 8 menunjukkan bahwa tiap variabel memiliki nilai koefisien total variance explained lebih besar dari 0,6. Hasil tersebut berarti pembentukan faktor memiliki indikasi yang kuat untuk diteliti dalam penelitian.

Menguji loading factor, maka nilai yang diperoleh harus minimal 0,5, yang berarti bahwa 50 persen varians dari variabel dapat dijelaskan oleh faktor yang terbentuk, sehingga nilai suatu variabel yang semakin kecil maka hubungannya dengan faktor yang terbentuk akan semakin lemah. Hasil uji loading factor secara rinci ditunjukkan pada Tabel 9 berikut.

Tabel 9. Hasil Uji Loading Factor

\begin{tabular}{cccccc}
\hline Iklan & $\begin{array}{c}\text { Loading } \\
\text { Factor }\end{array}$ & $\begin{array}{c}\text { Brand } \\
\text { Awareness }\end{array}$ & $\begin{array}{c}\text { Loading } \\
\text { Factor }\end{array}$ & Niat Beli & $\begin{array}{c}\text { Loading } \\
\text { Factor }\end{array}$ \\
\hline $\mathrm{X}_{1}$ & 0,870 & $\mathrm{M}_{1}$ & 0,896 & $\mathrm{Y}_{1}$ & 0,896 \\
$\mathrm{X}_{2}$ & 0,871 & $\mathrm{M}_{2}$ & 0,862 & $\mathrm{Y}_{2}$ & 0,886 \\
$\mathrm{X}_{3}$ & 0,907 & $\mathrm{M}_{3}$ & 0,912 & $\mathrm{Y}_{3}$ & 0,892 \\
$\mathrm{X}_{4}$ & 0,910 & $\mathrm{M}_{4}$ & 0,903 & $\mathrm{Y}_{4}$ & 0,928 \\
$\mathrm{X}_{5}$ & 0,929 & $\mathrm{M}_{5}$ & 0,859 & $\mathrm{Y}_{5}$ & 0,922 \\
\hline
\end{tabular}

Sumber: Data Primer Diolah, 2017

Tabel 9 menunjukkan bahwa masing-masing indikator pada tiap variabel memiliki nilai koefisien loading factor di atas 0,5. Hasil tersebut mengindikasikan bahwa masing-masing varians atau indikator pada tiap variabel dikatakan valid, sehingga dapat digunakan dalam penelitian.

Hasil analisis jalur persamaan regresi 1 dan 2 ditunjukkan pada Tabel 10 dan 11 berikut.

Tabel 10. Hasil Analisis Jalur Persamaan Regresi 1

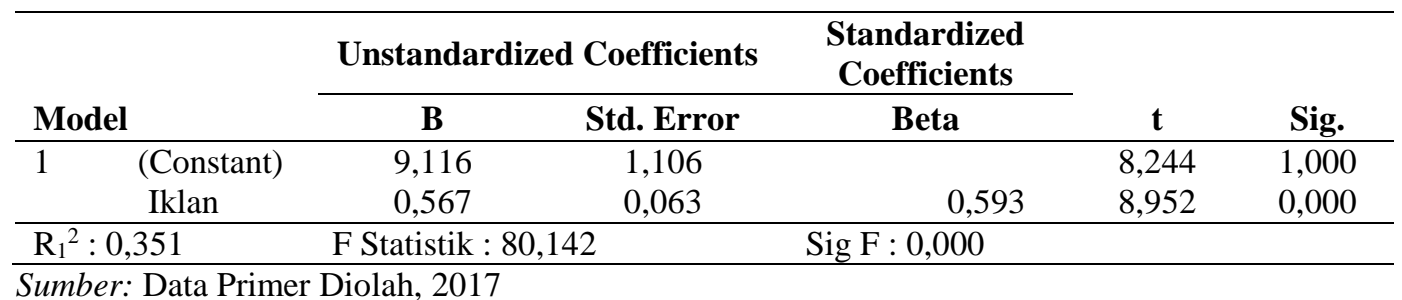


Hasil analisis jalur substruktur 1 telah disajikan pada Tabel 10, maka persamaan strukturalnya adalah sebagai berikut:

$$
\begin{aligned}
& M=\beta_{1} X+\varepsilon_{1} \ldots \ldots \\
& M=0,593 X+\varepsilon_{1}
\end{aligned}
$$

\begin{tabular}{|c|c|c|c|c|c|c|}
\hline \multirow{2}{*}{\multicolumn{2}{|c|}{ Model }} & \multicolumn{2}{|c|}{$\begin{array}{c}\text { Unstandardized } \\
\text { Coefficients } \\
\end{array}$} & \multirow{2}{*}{$\begin{array}{c}\begin{array}{c}\text { Standardized } \\
\text { Coefficients }\end{array} \\
\text { Beta }\end{array}$} & \multirow[b]{2}{*}{$\mathbf{t}$} & \multirow[b]{2}{*}{ Sig. } \\
\hline & & B & Std. Error & & & \\
\hline \multirow[t]{3}{*}{1} & (Constant) & $-0,843$ & 1,058 & & $-0,797$ & 0,427 \\
\hline & Iklan & 0,586 & 0,062 & 0,550 & 9,412 & 0,000 \\
\hline & Brand Awareness & 0,406 & 0,065 & 0,365 & 6,235 & 0,000 \\
\hline \multicolumn{2}{|c|}{$\mathrm{R}_{2}^{2}: 0,674$} & F Statistik & 151,862 & Sig. F : 0,000 & & \\
\hline
\end{tabular}

Tabel 11. Hasil Analisis Jalur Persamaan Regresi 2

Hasil analisis jalur substruktur 2 telah disajikan pada Tabel 11, maka persamaan strukturalnya adalah sebagai berikut:

$\mathrm{Y}=\beta_{2} \mathrm{X}+\beta_{3} \mathrm{M}+\varepsilon_{2}$

$$
\mathrm{Y}=0,550+0,365+\varepsilon_{2}
$$

Hasil analisis jalur substruktur 1 dan substruktur 2 telah dihitung, maka dapat disusun model diagram jalur akhir. Nilai standard error dihitung terlebih dahulu sebelum menyusun model diagram jalur akhir, yaitu sebagai berikut:

$$
\begin{aligned}
\varepsilon & =\sqrt{1-\mathrm{R}^{2}} \\
\varepsilon_{1} & =\sqrt{1-\mathrm{R}_{1}{ }^{2}} \\
& =\sqrt{1-0,351} \\
& =0,806 \\
\varepsilon_{2} & =\sqrt{1-\mathrm{R}_{2}{ }^{2}} \\
& =\sqrt{1-0,674} \\
& =0,571
\end{aligned}
$$


Standard error $(\varepsilon)$ telah dihitung, maka didapatkan hasil pengaruh $\operatorname{error}_{1}\left(\varepsilon_{1}\right)$ sebesar 0,806 dan pengaruh error $2\left(\varepsilon_{2}\right)$ sebesar 0,571. Perhitungan nilai koefisien determinasi total adalah sebagai berikut:

$$
\begin{aligned}
\mathrm{R}^{2} \mathrm{~m} & =1-\left(\mathrm{P} \varepsilon_{1}\right)^{2}\left(\mathrm{P} \varepsilon_{2}\right)^{2} \\
& =1-(0,806)^{2}(0,571)^{2} \\
& =1-(0,650)(0,326) \\
& =1-0,212 \\
& =0,788
\end{aligned}
$$

Nilai koefisien determinasi total sebesar 0,788 yang berarti bahwa sebesar 78,8 persen variasi niat beli dipengaruhi oleh variasi iklan dan brand awareness, sedangkan sisanya sebesar 21,2 persen dijelaskan oleh faktor lain yang tidak dimasukkan ke dalam model.

Hasil koefisien jalur pada hipotesis penelitian dapat digambarkan pada Gambar 2 berikut.

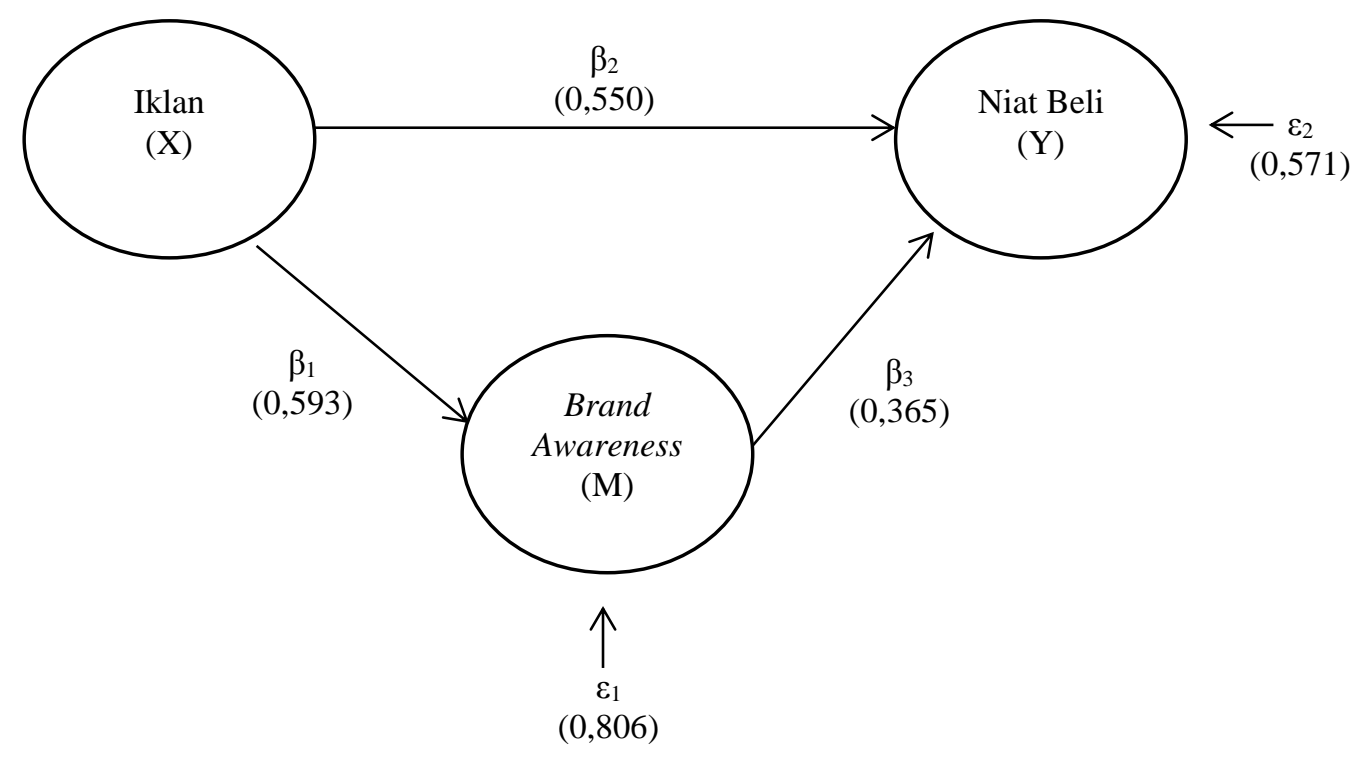

Gambar 2. Validasi Model Diagram Jalur Akhir

Sumber: Gambar Diolah, 2017 
Diagram jalur telah digambarkan pada Gambar 2, maka dapat dihitung besarnya pengaruh langsung, pengaruh tidak langsung serta pengaruh total antar variabel iklan, brand awareness, dan niat beli. Perhitungan pengaruh antar variabel ditunjukkan dalam Tabel 12 berikut.

Tabel 12. Pengaruh Langsung, Pengaruh tidak Langsung serta Pengaruh Total Iklan (X), Brand Awareness (M) dan Niat Beli (Y)

\begin{tabular}{cccc}
\hline $\begin{array}{c}\text { Pengaruh } \\
\text { Variabel }\end{array}$ & $\begin{array}{c}\text { Pengaruh } \\
\text { Langsung }\end{array}$ & $\begin{array}{c}\text { Pengaruh tidak Langsung Melalui Brand } \\
\text { Awareness } \\
(\mathbf{M})=\left(\boldsymbol{\beta}_{\mathbf{1}} \times \boldsymbol{\beta}_{\mathbf{3}}\right)\end{array}$ & $\begin{array}{c}\text { Pengaruh } \\
\text { Total }\end{array}$ \\
\hline $\mathrm{X} \rightarrow \mathrm{M}$ & 0,593 & - & 0,593 \\
$\mathrm{X} \rightarrow \mathrm{Y}$ & 0,550 & 0,216 & 0,766 \\
$\mathrm{M} \rightarrow \mathrm{Y}$ & 0,365 & - & 0,365 \\
\hline Sumber: Data Primer Diolah, 2017 & &
\end{tabular}

Hasil pada Tabel 12 memperlihatkan pengaruh langsung variabel iklan terhadap niat beli memiliki nilai koefisien beta sebesar 0,550 , sedangkan pengaruh tidak langsung yang dimediasi oleh brand awareness menunjukkan nilai koefisien beta sebesar 0,216. Hasil tersebut membuktikan bahwa brand awareness memediasi pengaruh iklan terhadap niat beli dengan pengaruh total yang diperoleh sebesar 0,766 .

Uji sobel dihitung menggunakan aplikasi Microsoft Excel 2010. Nilai standard error tidak langsung (indirect effect) atau $\mathrm{S}_{\mathrm{ab}}$ dihitung terlebih dahulu dengan rumus sebagai berikut:

$$
\mathrm{S}_{\mathrm{ab}}=\sqrt{\mathrm{b}^{2} \mathrm{Sa}^{2}+\mathrm{a}^{2} \mathrm{Sb}^{2}+\mathrm{Sa}^{2} \mathrm{Sb}^{2}}
$$

Keterangan:

$$
\begin{array}{ll}
\mathrm{a} & =0,567 \\
\mathrm{~S}_{\mathrm{a}} & =0,063 \\
\mathrm{~b} & =0,406 \\
\mathrm{~S}_{\mathrm{b}} & =0,065
\end{array}
$$




$$
\begin{aligned}
\mathrm{S}_{\mathrm{ab}} & =\sqrt{(0,406)^{2}(0,063)^{2}+(0,567)^{2}(0,065)^{2}+(0,063)^{2}(0,065)^{2}} \\
& =\sqrt{0,0020} \\
& =0,045
\end{aligned}
$$

Menguji pengaruh tidak langsung, maka nilai z dari koefisien ab dihitung dengan rumus sebagai berikut:

$$
\begin{aligned}
Z & =\frac{\mathrm{ab}}{\mathrm{Sab}} \ldots \ldots \ldots \ldots . \ldots \\
& =\frac{(0,567)(0,406)}{0,045} \\
& =\frac{0,230}{0,045} \\
& =5,11
\end{aligned}
$$

Hasil uji sobel yang telah dihitung menunjukkan bahwa nilai koefisien z adalah 5,11 > 1,96. Hasil tersebut berarti bahwa brand awareness memediasi pengaruh iklan terhadap niat beli.

\section{Pengaruh Iklan terhadap Brand Awareness}

Pengaruh antara iklan terhadap brand awareness telah diuji dalam penelitian ini, dimana nilai koefisien beta diperoleh sebesar 0,593 dengan tingkat signifikansi $0,000 \leq 0,05$ sehingga $\mathrm{H}_{0}$ ditolak dan $\mathrm{H}_{1}$ diterima, yang mengindikasikan bahwa iklan berpengaruh positif dan signifikan terhadap brand awareness. Hasil tersebut menunjukkan bahwa semakin baik iklan dalam menayangkan produk pasta gigi merek Sensodyne, maka tingkat brand awareness pada produk pasta gigi merek Sensodyne di Kota Denpasar juga semakin tinggi.

Hasil penelitian ini didukung dengan penelitian sebelumnya yang dilakukan oleh Odunlami dan Akinruwa (2014), Sawant (2012), serta Azaria dkk. (2014) yang 
menyatakan bahwa iklan berpengaruh positif dan signifikan terhadap brand awareness. Kesimpulan yang dapat ditarik bahwa iklan memiliki pengaruh yang positif dan signifikan terhadap brand awareness, sehingga dengan meningkatnya iklan yang bersifat positif terkait produk pasta gigi merek Sensodyne, maka akan meningkatkan pula brand awareness pada produk pasta gigi merek Sensodyne di benak konsumen.

\section{Pengaruh Iklan terhadap Niat Beli}

Pengaruh antara iklan terhadap niat beli dalam penelitian ini diperoleh nilai koefisien beta sebesar 0,550 dengan tingkat signifikansi $0,000 \leq 0,05$ sehingga $\mathrm{H}_{0}$ ditolak dan $\mathrm{H}_{2}$ diterima, yang mengindikasikan bahwa iklan berpengaruh positif dan signifikan terhadap niat beli. Hasil tersebut menunjukkan bahwa semakin baik iklan dalam memasarkan keunggulan produk pasta gigi merek Sensodyne, maka semakin tinggi pula tingkat niat beli pada konsumen terkait produk pasta gigi merek Sensodyne di Kota Denpasar.

Hasil penelitian ini diperkuat dengan penelitian sebelumnya yang dilakukan oleh Gunawan dan Dharmayanti (2014), Huang dan Dang (2014), serta Sularso dan Erviana (2012) yang menyatakan bahwa iklan berpengaruh positif dan signifikan terhadap niat beli. Kesimpulan yang dapat ditarik bahwa iklan memiliki pengaruh yang positif dan signifikan terhadap niat beli, sehingga dengan meningkatnya iklan yang bersifat positif terkait produk pasta gigi merek Sensodyne, maka akan meningkatkan pula niat beli produk pasta gigi merek Sensodyne pada konsumen. 


\section{Pengaruh Brand Awareness terhadap Niat Beli}

Pengaruh antara brand awareness terhadap niat beli dalam penelitian ini diperoleh nilai koefisien beta sebesar 0,365 dengan tingkat signifikansi $0,000 \leq 0,05$ sehingga $\mathrm{H}_{0}$ ditolak dan $\mathrm{H}_{3}$ diterima, yang mengindikasikan bahwa brand awareness berpengaruh positif dan signifikan terhadap niat beli. Hasil tersebut menunjukkan bahwa semakin tinggi tingkat brand awareness terkait produk pasta gigi merek Sensodyne, maka semakin tinggi pula tingkat niat beli pada konsumen terkait produk pasta gigi merek Sensodyne di Kota Denpasar.

Hasil penelitian ini serupa dengan penelitian sebelumnya yang dilakukan oleh Malik et al. (2013), Roozy et al. (2014), serta Kristanto dan Brahmana (2016) yang menyatakan bahwa brand awareness berpengaruh positif dan signifikan terhadap niat beli. Kesimpulan yang dapat ditarik bahwa brand awareness memiliki pengaruh yang positif dan signifikan terhadap niat beli, sehingga dengan meningkatnya brand awareness terkait produk pasta gigi merek Sensodyne di benak konsumen, maka akan meningkatkan pula niat beli pada konsumen terhadap produk pasta gigi merek Sensodyne.

\section{Peran Brand Awareness Memediasi Pengaruh Iklan terhadap Niat Beli}

Peran brand awareness memediasi pengaruh iklan terhadap niat beli pada produk pasta gigi merek Sensodyne telah diuji dalam penelitian ini. Hasil uji pengaruh iklan terhadap niat beli semula bernilai 0,550 , kemudian setelah adanya brand awareness sebagai variabel mediasi, nilai pada pengaruh iklan terhadap niat beli meningkat menjadi sebesar 0,766 . Uji sobel yang telah dihitung memperkuat hasil tersebut dengan nilai koefisien $\mathrm{z}$ yang diperoleh adalah 5,11 > 1,96 sehingga 
$\mathrm{H}_{0}$ ditolak dan $\mathrm{H}_{4}$ diterima, yang mengindikasikan bahwa brand awareness memediasi pengaruh iklan terhadap niat beli. Hasil tersebut menunjukkan bahwa brand awareness dinilai mampu memediasi pengaruh iklan terhadap niat beli produk pasta gigi merek Sensodyne di Kota Denpasar.

Hasil penelitian ini didukung dengan penelitian sebelumnya yang dilakukan oleh Prabawa dkk. (2017), Yudhiartika dan Haryanto (2012), serta Susilo dan Semuel (2015) yang menyatakan bahwa brand awareness secara signifikan mampu memediasi pengaruh iklan terhadap niat beli. Kesimpulan yang dapat ditarik bahwa iklan yang disertai oleh brand awareness akan mempengaruhi dan menentukan niat beli pada konsumen terhadap produk pasta gigi merek Sensodyne.

\section{Implikasi Dan Keterbatasan Penelitian}

Implikasi dari hasil penelitian ini menekankan pada manfaat nyata dalam menimbulkan niat beli bagi calon konsumen. Implikasi hasil penelitian yang didapat yaitu pertama, terbukti bahwa konsumen merasakan atau melihat iklan yang positif terkait produk pasta gigi merek Sensodyne pada indikator mengandung daya tarik dan menunjukkan manfaat. Produsen tetap harus dapat menjaga kualitas iklan produk pasta gigi merek Sensodyne, sehingga tayangan iklan tetap menarik dalam menyampaikan manfaat dan kelebihan produk pasta gigi merek Sensodyne itu sendiri.

Kedua, dalam penelitian ini konsumen merasakan brand awareness yang tinggi pada produk pasta gigi merek Sensodyne. Indikator pengetahuan konsumen akan kehadiran merek dan mengingat ciri khas merek menunjukkan bahwa konsumen telah sadar akan produk pasta gigi merek Sensodyne. Penting bagi 
produsen untuk tetap memperhatikan dan mempertahankan brand awareness produk pasta gigi merek Sensodyne di benak konsumen, agar produk pasta gigi merek Sensodyne selalu menjadi pilihan utama bagi konsumen dalam memenuhi atau mengatasi masalah gigi sensitif.

Ketiga, dalam penelitian yang telah diteliti ini diketahui bahwa konsumen memiliki niat beli yang positif pada produk pasta gigi merek Sensodyne. Indikator keinginan untuk memiliki produk dan ketertarikan untuk mencoba produk menunjukkan bahwa konsumen memiliki niat untuk membeli produk pasta gigi merek Sensodyne. Produsen diharapkan dapat meningkatkan kualitas dan keunggulan pada produk pasta gigi merek Sensodyne, agar konsumen yakin bahwa dengan menggunakan produk pasta gigi merek Sensodyne dapat mengatasi masalah gigi sensitif yang akan mendorong timbulnya niat beli pada konsumen terhadap produk pasta gigi merek Sensodyne.

Patut disadari bahwa terdapat keterbatasan dalam penelitian ini. Waktu yang cukup singkat dalam melakukan penelitian, sedangkan setiap saat tren, lingkungan, dan kebiasaan dapat berubah, maka penting untuk melakukan kembali penelitian ini. Ruang lingkup penelitian ini terbatas hanya pada wilayah Kota Denpasar, sehingga hasil penelitian untuk konsumen di luar wilayah Kota Denpasar tidak dapat digeneralisasi.

\section{SIMPULAN DAN SARAN}

Simpulan yang dapat diberikan berdasarkan pembahasan hasil penelitian yang telah dilakukan, bahwa iklan berpengaruh positif dan signifikan terhadap brand 
awareness. Hasil penelitian menunjukkan bahwa semakin baik iklan yang ditayangkan pada produk pasta gigi merek Sensodyne, maka akan meningkatkan brand awareness di benak konsumen terkait produk pasta gigi merek Sensodyne di Kota Denpasar.

Iklan berpengaruh positif dan signifikan terhadap niat beli. Hasil penelitian menunjukkan bahwa semakin baik iklan yang ditayangkan pada produk pasta gigi merek Sensodyne, maka akan meningkatkan niat beli pada konsumen terkait produk pasta gigi merek Sensodyne di Kota Denpasar.

Brand awareness berpengaruh positif dan signifikan terhadap niat beli. Hasil penelitian menunjukkan bahwa semakin meningkat brand awareness pada produk pasta gigi merek Sensodyne, maka niat beli produk pasta gigi merek Sensodyne di Kota Denpasar juga akan meningkat.

Brand awareness memediasi pengaruh iklan terhadap niat beli. Hasil penelitian menunjukkan bahwa kekuatan brand awareness turut mempengaruhi dan menentukan pengaruh dari iklan terhadap niat beli pada produk pasta gigi merek Sensodyne di Kota Denpasar.

Saran yang dapat diberikan berdasarkan kesimpulan yang diperoleh bagi pihak yang membutuhkan yaitu pertama, bagi pihak Sensodyne agar menambahkan testimoni produk pasta gigi merek Sensodyne dengan menggunakan celebrity endorser yang memiliki kredibilitas tinggi dalam tayangan iklan, sehingga dapat menjadi panggilan bagi konsumen untuk melakukan tindakan membeli terhadap produk pasta gigi merek Sensodyne. Kedua, bagi pihak Sensodyne untuk menyasar segmen ceruk pasar yang baru seperti memproduksi pasta gigi khusus mengatasi 
Vidya Chandra Dewi, Peran Brand Awareness Memediasi...

radang gusi, sehingga ketika konsumen memiliki masalah lain selain gigi sensitif yaitu masalah pada gusi, konsumen akan mengenal produk pasta gigi merek Sensodyne sebagai pasta gigi yang dapat mengatasi masalah pada gusi yang radang atau bengkak. Ketiga, bagi pihak Sensodyne agar menjadi sponsor dalam suatu kontes atau lomba yang akan mendorong rasa ingin tahu konsumen mengenai produk pasta gigi merek Sensodyne, sehingga nantinya dapat menimbulkan niat beli bagi konsumen terhadap produk pasta gigi merek Sensodyne.

\section{REFERENSI}

Andriyanto, Richard D., dan Haryanto, Jony O. 2010. Analisis Pengaruh Internet Marketing Terhadap Pembentukan Word of Mouth dan Brand Awareness untuk Memunculkan Intention to Buy. Jurnal Manajemen Teknologi, 9(1), $\mathrm{h}: 20-35$.

Azaria, P. A., Kumadji, S., dan Yaningwati, F. 2014. Pengaruh Internet Marketing Terhadap Pembentukan Word of Mouth dan Efektivitas Iklan dalam Meningkatkan Brand Awareness (Studi pada Follower Akun Twitter Pocari Sweat di Jejaring Sosial Twitter). Jurnal Administrasi Bisnis (JAB), 13(1), h:1-7.

Barr, S. 2007. Factors Influencing Environmental Attitudes and Behaviors. Environment and Behavior, 39(4), pp:435-473.

Bendixen, Mike T. 1993. Advertising Effects and Effectiveness. European Journal of Marketing, 27(10), pp:19-32.

Chi, Hsin Kuang, Yeh, Huery Ren, and Yang, Ya Ting. 2009. The Impact of Brand Awareness on Consumer Purchase Intention: The Mediating Effect of Perceived Quality and Brand Loyalty. The Journal of International Management Studies, 4(1), pp:135-144.

CNI. 2017. Pentingnya Menjaga Kesehatan Gigi dan Mulut. http://www.cni.co.id/index.php/corporate-info/news/info-cni/l638pentingnya-menjaga-kesehatan-gigi-dan-mulut. Diunduh tanggal 1 April 2017. 
Dewa, Chriswardana B. 2015. Pengaruh Country of Origin Produk Televisi LG Terhadap Niat Beli Konsumen Dengan Ekuitas Merek Sebagai Variabel Pemediasi. Jurnal Bianglala Informatika, 3(1), h:74-82.

Djatnika, Tjetjep. 2007. Komunikasi Pemasaran. Bandung: PT Remaja Rosdakarya.

Durianto, Darmadi., Sugiarto, dan Budiman, Lie Joko. 2004. Brand Equity Ten. Jakarta: PT. Gramedia Pustaka Utama.

Eriko, R., Setiaman, A., dan Benyamin, P. 2012. Tayangan Iklan Produk dalam Membangun Kesadaran Merek. E-Jurnal Mahasiswa Universitas Padjadjaran, 1(1), h:1-18.

Ering, Merry C., dan Pandowo, M. 2015. Analisa Komunikasi Pemasaran dan Efeknya pada Minat Beli Konsumen Emas di PT. Pegadaian (Persero) Cabang Manado Utara. Jurnal EMBA, 3(2), h:776-786.

Fisamawati. 2014. Adu Kekuatan di Pasar Gigi Sensitif. http://www.marketing.co.id/adu-kekuatan-di-pasar-pasta-gigi-sensitif/. Diunduh tanggal 12 Maret 2017.

Gunawan, F. A., dan Dharmayanti, D. 2014. Analisis Pengaruh Iklan Televisi dan Endorser terhadap Purchase Intention Pond's Men dengan Brand Awareness sebagai Variabel Intervening. Jurnal Manajemen Pemasaran Petra, 2(1), h:114.

Hemamalini, K. S., and Kurup, S. K. 2014. Effectiveness of Television Advertisement on Purchase Intention. International Journal of Innovative Research in Science, Engineering and Technology, 3(2), pp:9416-9422.

Hoyer, W. D., and Brown, S. P. 1990. Effect of Brand Awareness on Choice for a Common, Repeat-purchase Product. Journal of Consumer Research, 17, pp:141-148.

Huang, Y. F., and Dang, H. S. 2014. An Empirical Analysis on Purchase Intention on Coffee Beverage in Taiwan. European Journal of Business and Management, 6(36), pp:182-196.

Humdiana. 2005. Strategi Pemasaran. Jakarta: PT Gramedia Pustaka Mizan Pustaka.

Jalilvand, M. R., Samiei, N., and Mahdavinia, S. H. 2011. The Effect of Brand Equity Components on Purchase Intention: An Application of Aaker's Model in the Automobile Industry. International Business and Management, 2(2), pp:149158. 
Kalis, Gerardus Septian. 2017. 33 Persen Orang Indonesia Alami Gigi Sensitif. http://www.klikdokter.com/info-sehat/read/3087417/33-persen-orangindonesia-alami-gigi-sensitif. Diunduh tanggal 25 September 2017.

Kotler, Philip. 2005. Manajemen Pemasaran. Jakarta: Erlangga.

Kotler, Philip, dan Amstrong, Gary. 2012. Prinsip-prinsip Pemasaran. Edisi 13. Jilid 1. Jakarta: Erlangga.

Kristanto, Harris, dan Brahmana, Ritzky Karina M. R. 2016. Pengaruh Product Placement pada Film Indonesia Terhadap Brand Awareness dan Purchase Intention Masyarakat Surabaya. Jurnal Manajemen Pemasaran, 10(1), h:2026.

Liwe, Farli. 2013. Kesadaran Merek, Keragaman Produk, dan Kualitas Produk Pengaruhnya Terhadap Pengambilan Keputusan Konsumen Membeli di Kentucky Fried Chicken Manado. Jurnal EMBA, 1(4), h:2107-2116.

Malik, E. M., Ghafoor, M. M., Iqbal, H. K., Riaz, U., Hassan, N., Mustafa, M., and Shahbaz, S. 2013. Importance of Brand Awareness and Brand Loyalty in assessing Purchase Intentions of Consumer. International Journal of Business and Social Science, 4(5), pp:167-171.

Odunlami, B. I., and Akinruwa, T. E. 2014. Effect of Promotion on Product Awareness (A Case Study of a Reputable Organization in the Brewery SubSector of the Manufacturing Industry. International Journal of Education and Research, 2(9), pp:451-472.

Okezone. 2017. Tren Gaya Hidup Sehat jadi Peluang, Cicipi Bisnis Katering hingga Pelatih Olahraga. https://economy.okezone.com/read/2017/09/14/320/1775931/tren-gayahidup-sehat-jadi-peluang-cicipi-bisnis-katering-hingga-pelatih-olahraga. Diunduh tanggal 25 September 2017.

Prabawa, Kadek T. S., Sukawati, Tjok G. R., dan Setiawan, P. Y. 2017. Peran Brand Awareness dalam Memediasi Hubungan Iklan dan Personal Selling dengan Niat Beli. E-Jurnal Manajemen Unud, 6(2), h:889-918.

Priya, P., Baisya, R. K., and Sharma, S. 2010. Television Advertisements and Children's Buying Behaviour. Marketing Intelligence \& Planning, 28(2), pp:151-169.

Rangkuti, Freddy. 2002. The Power of Brands, Teknik Mengelola Brand Equity dan Strategi Pengembangan Merek. Jakarta: Gramedia Pustaka. 
Rina, Sri Nova. 2014. Pengaruh Daya Tarik Iklan dan Frekuensi Penayangan Iklan Terhadap Intensi Pembelian Happy Call Lejel Home Shopping. Jurnal Kompetitif, 3(2), h:133-149.

Roozy, E., Arastoob, M. A., and Vazifehdust H. 2014. Effect of Brand Equity on Consumer Purchase Intention. Indian J.Sci.Res., 6(1), pp:212-217.

Sawant, Roshni P. 2012. Impact of Advertising on Brand Awareness and Consumer Preference (with Special Reference to Men'S Wear). Journal of Business and Management (IOSR-JBM), 5(6), pp:54-61.

Schiffman, Leon G., dan Kanuk, Leslie Lazar. 2004. Perilaku Konsumen. Edisi ke 7. Jakarta: Prentice Hall.

Sensodyne. 2017. Sensodyne. https://www.sensodyne.co.id/. Diunduh tanggal 10 April 2017.

Shimp, T. A. 2014. Komunikasi Pemasaran Terpadu dalam Periklanan dan Promosi. Edisi 8. Jakarta: Salemba Empat.

Sugiardi, Agustin Bayu, dan Harti. 2017. Pengaruh Iklan dan Atribut Produk Terhadap Brand Awareness pada Produk Hufagripp. Jurnal Pendidikan Tata Niaga (JPTN), 3(3), h:30-35.

Sugiyono. 2014. Metode Penelitian Bisnis: Pendekatan Kualitatif, Kuantitatif, dan $R \& D$. Bandung: Alfabeta.

Sularso, R. A., dan Erviana. 2012. Pengaruh Promosi Terhadap Niat Beli Konsumen Telkom Speedy di Area Surabaya. Jurnal ISEI Jember, 2(1), h:928.

Susilo, I., dan Semuel, H. 2015. Analisa Pengaruh Emotional Marketing terhadap Purchase Intention melalui Brand Awareness pada Produk Dove Personal Care di Surabaya. Jurnal Manajemen Pemasaran, 9(1), h:23-34.

Tandjung, Jenu Wijaya. 2004. Marketing Management: Pendekatan pada Nilainilai Pelanggan. Malang: Bayumedia.

Vejačka, Martin. 2012. Facebook Advertising and Its Efficiency on the Slovak Market. Marketing a Obchod, 15(1), pp:116-127.

Web Kesehatan. 2017. Gigi Sensitif - Penyebab dan Cara Mengatasinya. https://www.webkesehatan.com/gigi-sensitif/. Diunduh tanggal 27 September 2017. 
Vidya Chandra Dewi, Peran Brand Awareness Memediasi...

Wijaya, Bambang Sukma. 2011. The Development of Hierarchy of Effect Model in Advertising. International Research Journal of Business Studies, 5(1), pp:7385.

Yoo, Boonghee., Donthu, Naveen., and Lee, Sungho. 2000. An Examinition of Selected Marketing Mix Elements and Brand Equity. Journal of the Academy Marketing Science, 28(2), pp:195-211.

Yudhiartika, D., dan Haryanto, J. O. 2012. Pengaruh Personal Selling, Display, Promosi Penjualan terhadap Brand Awareness dan Intensi Membeli pada Produk Kecantikan Pond's. Buletin Studi Ekonomi, 17(2), h:142-156. 